CHAPTER 4.7.

\title{
USING GEOGRAPHIC INFORMATION SYSTEMS AND SPATIAL MODELLING IN AREA-WIDE INTEGRATED PEST MANAGEMENT PROGRAMMES THAT INTEGRATE THE STERILE INSECT TECHNIQUE
}

\section{J. BOUYER ${ }^{1,3}$, J. ST. H. COX ${ }^{2}$, L. GUERRINI ${ }^{3}$, R. LANCELOT ${ }^{3}$,} A. H. DICKO ${ }^{3}$ AND M. J. B. VREYSEN ${ }^{1}$

${ }^{1}$ Joint FAO/IAEA Division of Nuclear Techniques in Food and Agriculture, International Atomic Energy Agency, A-1400 Vienna, Austria

Email: J.Bouyer@iaea.org

${ }^{2}$ Bill and Melinda Gates Foundation, Seattle, WA 98102, USA, and USAIDFID Malaria Knowledge Programme, Infectious and Tropical Diseases, London School of Hygiene and Tropical Medicine, London WC1E 7HT, UK

${ }^{3}$ Unité de Recherche Animal, Santé, Territoires, Risques et Écosystèmes, CIRAD, 34398 Montpellier, France

\section{TABLE OF CONTENTS}

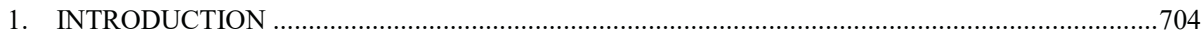

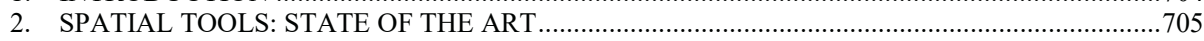

2.1. Geographic Information Systems (GIS) …………........................................................705

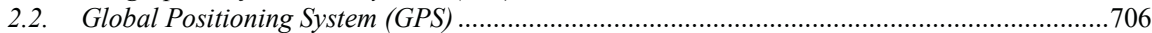

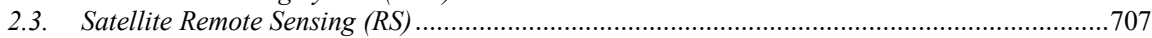

3. APPLICATION AREAS FOR GIS, GPS, AND RS IN OPERATIONAL PROGRAMMES .............710

3.1. Planning and Implementing Pre-Intervention (Insect, Disease, Host) Surveys GIS-Based Modelling of Spatial Distribution of Target Insects ...............................................710

3.1.1. Mapping Pest Distribution on a Regional Scale .....................................................711

3.1.2. GIS for Decision Support ………………………….......................................712

3.1.3. Mapping Pest Density with a Large Spatial Resolution …………………………....713 


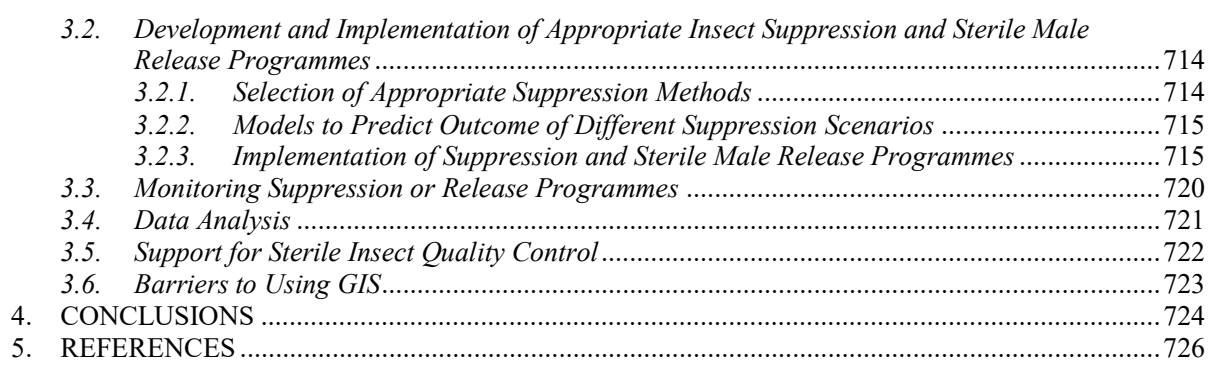

SUMMARY

Geographic information systems (GIS) and spatial modelling are crucial for designing, implementing, and optimizing area-wide programmes of insect and/or disease control. This chapter provides a basic introduction to the science of GIS, Global Positioning System (GPS), satellite remote sensing (RS), and spatial modelling, and reviews the principal ways in which these technologies can be used to assist various stages of development of the sterile insect technique (SIT) as part of area-wide integrated pest management (AW-IPM) programmes - from the selection of project sites, and feasibility assessments and planning of pre-intervention surveys, to the monitoring and analysis of insect suppression programmes, and the release of sterile insects. Potential barriers to the successful deployment of GIS tools are also discussed.

\section{INTRODUCTION}

The success of the sterile insect technique (SIT) and other area-wide interventions, aimed at controlling populations of insect pests, depends to a large degree on appropriate project planning and implementation. More specifically, successful programmes depend on an accurate knowledge of pre-existing distributions of insects in time and space, on the appropriate design of insect suppression strategies and sterile insect release projects, and on the development of suitable frameworks for monitoring and evaluation. Methods and tools have become available that enable the development of models simulating the demography of a metapopulation of insects, thus making the ex-ante assessment of various control strategies possible (Peck 2012; Peck and Bouyer 2012).

Geographic Information Systems (GIS), the Global Positioning System (GPS), remote sensing (RS), and spatial modelling are allied technologies that together provide a means of gathering, integrating, and analysing spatial data. These tools are already being used extensively in other areas of agroecological management and epidemiological research (Barnes et al. 1999; Nutter et al. 2002; Moiroux et al. 2013; Tsafack et al. 2013; Dicko et al. 2015), and their use within area-wide integrated pest management (AW-IPM) programmes (Adam et al. 2013; Percoma et al. 2016) including those with an SIT component is growing quickly (Bouyer et al. 2010; Dicko et al. 2014). The tools are becoming increasingly accessible to non-specialists thanks to a wide range of freeware (FAO/IAEA 2006).

The principal aim of this chapter is to present applications of GIS and associated spatial tools within AW-IPM programmes. The first part of the chapter constitutes a short primer on GIS, GPS, and RS technologies. Subsequent sections illustrate the use of these tools in ecological and epidemiological studies, and address issues specific to 
area-wide programmes integrating the SIT, particularly with respect to the use of spatial tools in feasibility assessments, planning and implementing pre-intervention surveys, and guiding the subsequent operational programmes of insect suppression and sterile insect release.

\section{SPATIAL TOOLS: STATE OF THE ART}

\subsection{Geographic Information Systems (GIS)}

GIS can be defined as computer-based systems capable of capturing, cleaning (checking for errors and gaps), integrating, storing, retrieving, analysing, and displaying spatial data. GIS incorporate spatial data (geographical features) in the form of geographical coverages (maps), and descriptive data (attributes) in the form of relational databases linked to the mapped features (Kitron 1998).

GIS coverages can be developed using information from a variety of sources, including digitized paper maps, field surveys using hand-held GPS receivers, and thematic layers derived from remote sensing. Much of the utility of GIS stems from their ability to combine datasets of different provenances, spatial scales, and data types. Most, if not all, of these applications have become freely available in generalpurpose computing environments such as R (Bivand et al. 2008).

In most GIS packages, geographic data are represented by vector and raster data models. In the vector model, geographical features are represented by points, or as lines and polygons made up of points joined by lines (arcs). In the raster model, spatial data comprise a regular grid of cells in which points are represented as single cells, and lines as strings of connected cells. Raster data are better suited to storing and modelling variables that vary continuously in space (Bonham-Carter 1994). Topographic data, for example, are commonly stored as raster grids (digital elevation models). Climate data, which vary continuously in space and time, are also commonly stored as rasterized climate "surfaces" (Hutchinson et al. 1995) or raster stacks combining hundreds or thousands of elementary rasters (Anyamba et al. 2014). Most GIS software packages can handle both vector and raster data, which are complementary and frequently used jointly.

GIS can be used for their mapping and visualization capabilities, or for much more sophisticated forms of spatial and statistical analysis. In this context, spatial analysis refers to the manipulation and transformation of GIS data to extract additional meaning from them. Common examples of spatial analysis include buffering map features (e.g. to define areas of exposure (potential infestation) around insect-breeding sites), interpolating between points (e.g. to produce climate "surfaces" from a network of weather stations), overlaying a number of individual geographical coverages to produce derivative maps, or even spatial modelling of suitable landscapes for target insect species, insect distribution or density. The latter approach can often take the form of "suitability analysis", in which spatial coverages are weighted and combined to identify and display locations that meet specific criteria (Clarke et al. 1996). Later in this chapter, an example is described in which suitability analysis has been used for decision support in trypanosomosis control. Several introductory texts provide more detail on the range of spatial analytical techniques 
available in most GIS packages (Bonham-Carter 1994; Burrough and McDonnell 1998).

GIS software and general-purpose computing environments now commonly include a range of geostatistical commands and specialized add-on packages allowing basic as well as sophisticated spatial analyses, including testing for space-time clustering among point and polygon data (Pfeiffer and Hugh-Jones 2002; Bivand et al. 2008). This type of exploratory data analysis is particularly appropriate for identifying unusual spatial patterns within large datasets, and is often used as a means of hypothesis generation.

The accuracy of the final output from a GIS-based analysis is, to a significant degree, determined by the quality of the data in the GIS. The spatial and temporal resolutions of the data used in GIS need to be appropriate for the application in question. For example, topographic maps at a scale of 1:250 000 would be of little use in a village-scale study. Similarly, a series of annual climate surfaces would be illsuited to attempts to determine the seasonality of insect populations. Hand-held GPS receivers for ground assessment and validation, and satellite remote sensing for updated information on changes in surface conditions, have become easily accessible for pest control programmes.

\subsection{Global Positioning System (GPS)}

Hand-held GPS receivers are ideally suited to mapping spatial features where conventional maps are unavailable or inadequate (Thomson and Connor 2000). The basis of the GPS is a constellation of 24 NAVSTAR satellites developed and maintained by the US Department of Defense. These satellites act as reference points, with each satellite transmitting a radio signal in the form of pseudo-random code. On the ground, GPS receivers use this code to determine distances to each satellite ("ranging"), and calculate their position and altitude by "trilaterating" signals from a number of satellites. A European alternative named "Galileo" was launched in May 2016 with two new satellites, and will allow much more accurate positioning, but it will not be available before 2020 .

GPS receivers typically achieve a horizontal accuracy in the 5-15 $\mathrm{m}$ range. Positional errors arise mainly from atmospheric effects on the GPS signals, from clock errors, and as a result of multipath reflection of signals at ground level. Much of the error due to atmospheric effects can be removed using "differential" GPS techniques, in which positions obtained from a roving GPS are corrected using signals received by a static GPS located at an accurately surveyed position. Horizontal accuracy using differential GPS techniques is usually in the 1-5 $\mathrm{m}$ range, although sub-metre accuracy can also be achieved depending on the hardware used. However, in most ecological or entomological survey situations, a positional error of 5-15 $\mathrm{m}$ is probably acceptable.

GPS receivers are often used simply to collect spatial data (coordinates) for geographical features, with associated attribute data recorded separately and manually on survey forms. However, in many cases, GPS-receiver software now includes programmable "data dictionaries" which can be used to capture attribute information directly. Alternatively, some GPS receivers can be linked up to other devices such as 
a tablet or a notebook computer. Both approaches greatly increase the speed and efficiency with which GPS data can subsequently be incorporated into existing GIS.

It is also possible to upload the results of spatial modelling, like suitable habitats for insects (see below), using a GPS to guide operational teams toward specific sites used for monitoring (Bouyer et al. 2010) or control (Dicko et al. 2014).

\subsection{Satellite Remote Sensing (RS)}

Satellite RS is the process of gathering information about the earth's surface using electromagnetic sensors on board satellites. Sensors can be "passive", e.g. Spot, Landsat, and Meteosat satellites, in the sense that they detect solar radiation reflected from the earth's surface, or "active", e.g. radar, which provide their own energy source for illumination, and the reflected radiation is measured by the sensor. The latter have rarely been applied in ecological and epidemiological studies. Data from passive sensors can be used in a relatively raw form, e.g. to derive land-cover classification maps, or can be transformed into indices that constitute direct proxies (substitutes) for environmental variables, such as rainfall, land-surface temperature, and vegetation status (Hay et al. 1996).

The value of satellite RS for ecological research has long been recognized, particularly in terms of its ability to offer objective, up-to-date assessments of surface conditions over large, sometimes inaccessible, areas. Moreover, the repeatability of satellite measurements makes RS particularly suitable for monitoring environmental conditions over time. The applicability of remote sensing to different types of ecological study will, however, depend on both the nature of the study and the spatial, temporal, and spectral characteristics of available image data (Box 1).

Images from different sensors vary greatly in terms of spatial resolution, e.g. with pixel sizes for commonly available products currently ranging from under a square metre to several square kilometres. Similarly, the temporal resolution (or revisit time) of individual sensors can be as little as 30 minutes in the case of geostationary meteorological satellites, or as much as 30 days in the case of some polar-orbiting satellites. Near-polar orbit satellites such as Landsat, Spot, or Moderate-resolution Imaging Spectroradiometer (MODIS) offer intermediary temporal resolutions, and are the most frequently used. In a project that requires local, detailed assessments of land cover, spatial resolution will be the prime consideration when selecting satellite data. If the project is more concerned with changing meteorological and vegetation patterns over time, temporal resolution will be of greater concern.

Species distribution modelling is increasingly based on the combination of high spatial and temporal resolution data, particularly MODIS data (Hartemink et al. 2011; Dicko et al. 2014).

In the context of ecological and epidemiological studies, satellite data have been extensively used to model and predict the distributions of insects and/or associated diseases in time and space (Rogers and Randolph 1986; Rogers et al. 1996; Linthicum et al. 1999; Moiroux et al. 2013; Dicko et al. 2015). Modelling on a large scale has commonly involved using satellite data to delimit specific insect-breeding sites or habitats (Linthicum et al. 1987; Pope et al. 1994; Rejmankova et al. 1995). On a national or regional scale, these distributions are more commonly modelled on the 
basis of proxies for meteorological variables and/or vegetation status (Linthicum et al. 1987, 1990; Rogers et al. 1996; Hay et al. 1998; Brooker and Michael 2000; Randolph 2000). Several general reviews, covering these and other studies, are available (Thomson and Connor 2000; Hay et al. 2006).

\section{Box 1. Resolution in Satellite Remote Sensing \\ Spatial Resolution (Fig. 1)}

The spatial resolution (pixel size) of various sensors varies enormously: 0.61-2.4 m for QuickBird, 5$10 \mathrm{~m}$ for SPOT 5, 15-90 m for ASTER, 15-60 m for Landsat, 250-2000 m for MODIS. The width (swath) of images varies accordingly, e.g. about $25 \mathrm{~km}$ for QuickBird, $185 \mathrm{~km}$ for Landsat. Polarorbiting meteorological satellites have relatively low spatial resolutions and large swath widths $(1.1 \mathrm{~km}$ and about $2400 \mathrm{~km}$, respectively, for AVHRR), while images from Meteosat and other geostationary meteorological satellites have $1-8 \mathrm{~km}$ pixels, but comprise an entire earth half-disk.

\section{Temporal Resolution}

Temporal resolution is defined by the time taken for a satellite to revisit the same point in its orbit (repeat time). Sensors with high spatial resolutions tend to have low orbits and long repeat times, e.g. 16 and 26 days in the case of Landsat and SPOT satellites, respectively. Since over a year's period some satellites sense only a few images for a given locality, obtaining cloud-free data can be problematic. At the other extreme, meteorological satellites have very short repeat times (12 hours for AVHRR, 30 minutes for Meteosat), and obtaining cloud-free data is rarely a problem.

\section{Spectral Resolution}

Passive sensors detect radiation from the sun that has been reflected by the earth's surface (as well as, in some cases, radiation emitted directly from earth). The amount of reflected radiation depends on the nature of the surface and on the wavelength of the radiation concerned. For example, vegetation reflects most of the radiation it receives in the green (visible) part of the electromagnetic spectrum, but absorbs much of infrared energy. Dry soil, on the other hand, absorbs large amounts of visible light, but reflects a large proportion of near infrared. The ability to use these "spatial signatures" to infer surface properties depends on the spectral resolution of the remote-sensing data being used. Spectral resolution refers to the number, width and spacing of the spectral "bands" used by the sensor. Traditionally, most sensors have included three to seven bands in the visible and near-to-thermal infrared part of the electromagnetic spectrum (0.3-14-mm wavelengths). However some new sensors, e.g. MODIS and ASTER, have many more, and this improved spectral resolution should increase the ability to distinguish between different land-cover types.

Long-standing sensors, such as the National Oceanographic and Atmospheric Administration's Advanced Very-High-Resolution Radiometer (AVHRR), or the MODIS on NASA's Terra satellite, are helping to bridge existing gaps in data availability by providing data at both moderate spatial and temporal resolutions (250$2000 \mathrm{~m}$, and daily, respectively, in the case of MODIS). Another Terra sensor, ASTER, provides imagery with a spatial resolution similar to Landsat and SPOT data (15-30 $\mathrm{m}$ in visible and near-infrared bands), but with a vastly superior spectral resolution. Commercial satellites now also provide relatively low-cost data at very high spatial resolutions. For example, data from Digital Globe's QuickBird sensor has a spatial resolution of $0.61 \mathrm{~m}$ in panchromatic mode and $2.4 \mathrm{~m}$ in multispectral mode. SPOT images offer a good compromise between spatial resolution and coverage. Pléiades 1A (launched in 2011), Pléiades 1B (launched in 2012), and SPOT 7 satellites (launched in 2014) deliver images at very high spatial resolution $(0.5 \mathrm{~cm}$ and $1.5 \mathrm{~m})$. 

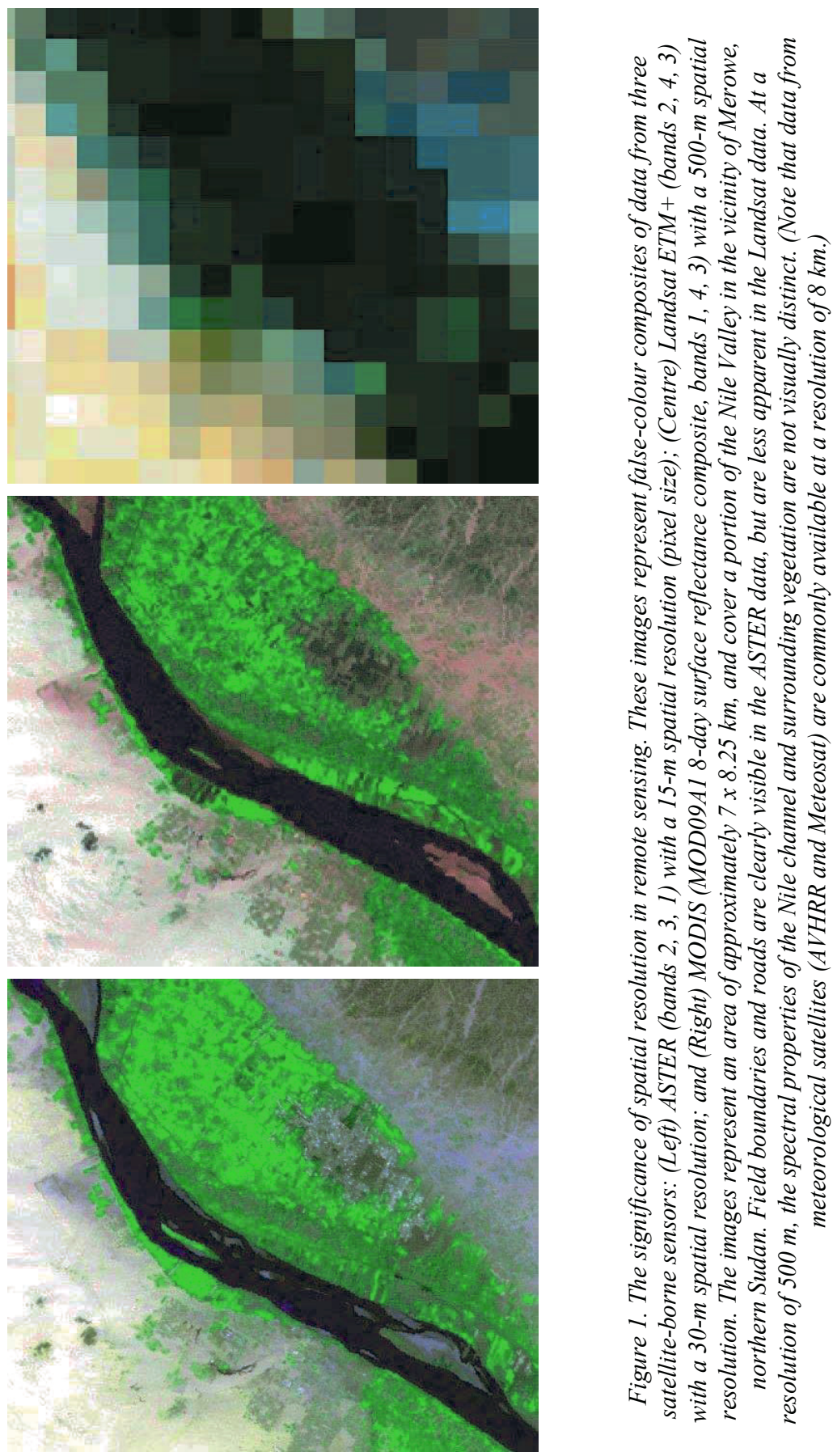
By improving the accuracy and coverage, taking into consideration temporal and geographic requirements, current satellite imagery is ideally suited for disease/vector control programmes at regional, national or smaller scale. Thematic layers like hydrographic networks, human or animal densities, tree cover, and vegetation classification are available on the web and can be used for operational programmes (Cecchi and Mattioli 2009; Stevens et al. 2015; Nicolas et al. 2016). However, it is crucial to validate the various layers in the field depending on its intended specific use, particularly in the case of vegetation layers that should be validated depending on the ecology of the target insect species (Guerrini et al. 2008, 2009).

\section{APPLICATION AREAS FOR GIS, GPS, AND RS IN OPERATIONAL PROGRAMMES}

There is enormous potential to use powerful analytical frameworks in spatial decision-support systems in AW-IPM programmes, which can take decision-makers beyond the point of simply possessing data, information, and knowledge.

Individually, GIS, GPS, and RS potentially have several important roles to play at various stages of project planning and implementation. The following sections illustrate how these technologies can be used to prioritize areas for control operations or to optimize these operations. Several key individual stages of project planning and implementation are addressed, from the design of pre-intervention surveys to monitoring and analysing data from insect release programmes.

\subsection{Planning and Implementing Pre-Intervention (Insect, Disease, Host) Surveys - GIS-Based Modelling of Spatial Distribution of Target Insects}

Insect pest control programmes, integrating a combination of suppression techniques, require accurate, up-to-date information on the spatial and temporal distribution of the target insect population. A spatially-explicit analysis can bring together a wide range of information sources - e.g. climate data, remote-sensing data, land-use and topographic data, historical data on insect distribution and abundance, disease prevalence, etc. - that together can be used to develop modelled or empirical estimates of the temporal and spatial distributions of the pest or disease. The nature of this spatial analysis, and the data sources used for it, will reflect the stage to which pre-intervention planning has developed. At the very early stages of feasibility assessment and planning, for example, spatial modelling will focus on identifying areas of relatively high pest density or areas where intervention programmes have potentially high benefit-cost ratios (Mumford, this volume) at the national or regional level, using low spatial resolution data for climate and medium or high spatial resolution data for land cover in combination with available historical information on the insects and/or diseases. These maps may be adequate for planning purposes in cases where insect intervention programmes are implemented at the national or regional scale. In other cases, it may be more appropriate to use these broad assessments for directing more detailed modelling efforts, using higher-resolution geographic datasets to focus sampling of insects to specific areas of interest. 


\subsubsection{Mapping Pest Distribution on a Regional Scale}

Many published research studies have used GIS and RS to predict the distribution of insects on national to global scales (Hay et al. 2006; Rogers 2006). The discussion here is limited to work most pertinent to using the SIT in the context of AW-IPM programmes, most of which has focused on the spatial prediction of tsetse flies Glossina spp.

The use of low-spatial-resolution satellite data to predict insect distributions dates back to attempts in the early 1990s to correlate the distribution of tsetse and the incidence of trypanosomosis to spatial variations in climate and the normalized difference vegetation index (NDVI) (Rogers 1991; Rogers and Randolph 1991; Rogers and Williams 1993). Later models also incorporated surrogates of landsurface temperature from AVHRR satellite data, and a proxy variable for rainfall (cold-cloud duration) from Meteosat data. Rogers et al. (1996), for example, used Fourier-processed satellite data for climate and NDVI in combination with digital elevation data to predict the presence/absence of eight tsetse species in Côte d'Ivoire and Burkina Faso, with an accuracy of $67-100 \%$.

A similar approach, using logistic regression, has also been used to model ranges of tsetse species in East Africa. The modelling process relies on the logistic regression of fly presence against a wide range of predictor variables for a large number of regularly spaced sample points for each area. The predictor variables include remotely sensed (satellite image) surrogates of climate - vegetation, temperature, and moisture, which have been subjected to Fourier processing to provide an additional set of season- and timing-related measures for each parameter. Demographic, topographic, and agro-ecological predictors are also used. These models are then applied to the predictor imagery to produce predicted probabilities of fly distributions at $1-\mathrm{km}$ resolution.

In southern Africa, Robinson et al. (1997) used climate surfaces, together with NDVI and elevation, to model the distributions of three tsetse species in the common fly belt. Maximum-likelihood classification techniques yielded overall correct predictions of 92.8 and $85.1 \%$ for Glossina morsitans centralis Machado and Glossina morsitans morsitans Westwood, respectively. In Togo, Hendrickx et al. (2001) found that discriminant models, based on satellite data, were generally less successful at predicting disease outcomes in cattle (trypanosomosis prevalence or packed-cell volume) than tsetse abundance.

More recently, MaxEnt models have been used extensively to predict tsetse suitable habitats in southern (Matawa et al. 2013) and western Africa (Bouyer et al. 2015; Dicko et al. 2015). MaxEnt, one of the most widely used species distribution models, is a machine-learning method based on the information theory concept of maximum entropy (Elith et al. 2011). MaxEnt fits a species distribution by contrasting the environmental conditions where the species is present to the global environment characterized by some generated pseudo-absence data, also called the background. The logistic output gives us a quantitative indicator of the habitat preferences of the species in the study area (Fig. 2). In West Africa it was used, together with a friction model to predict the resistance of landscape to tsetse dispersal (Krafsur and Ouma, this volume), to identify isolated populations of Glossina palpalis gambiensis Vanderplank that could be potential targets for eradication. 


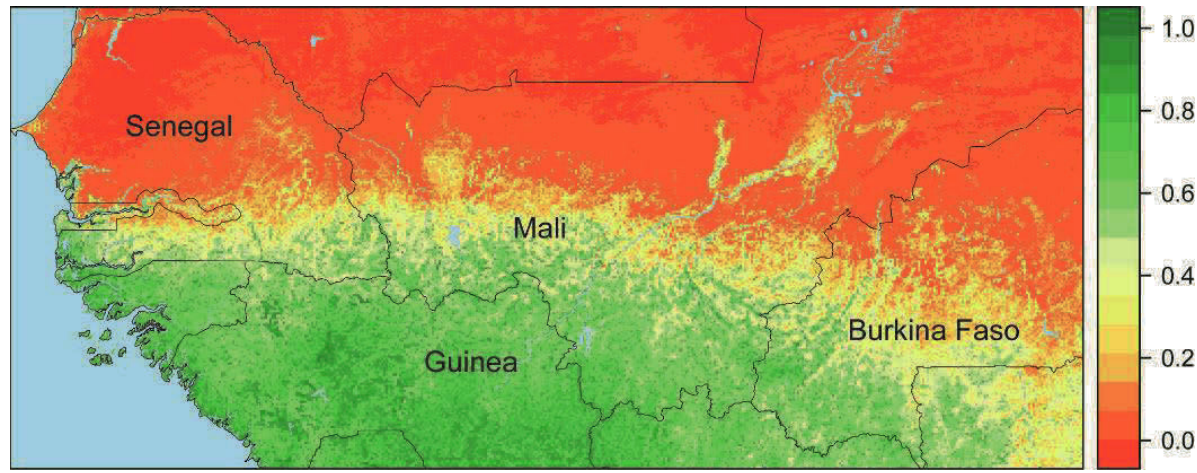

Figure 2. Distribution of G. p. gambiensis in West Africa. Mean habitat suitability index predicted by a MaxEnt model. The index varies between 0 (less suitable, red scale) and 1 (highly suitable, green scale). (Modified from Bouyer et al. 2015, reproduced with permission.)

High predictive accuracy in prediction models requires recent and well-distributed insect data to train and validate the prediction process, and assess the accuracy of the model output. Models based on entomological data that were collected several decades ago may be used for regional prioritization of tsetse and trypanosomosis interventions but, because of their poor sensitivity and specificity, should be avoided for guiding control programmes (Guerrini et al. 2009).

Data on insect abundance is even more sensitive because the efficiency of traps depends largely on environmental conditions, period of the year, experience of the entomological team, etc. At the continental or regional scale, it could be argued that the relative risk of insect presence is an adequate indicator of abundance. However, this assumption is not valid for smaller areas, where models require up-to-date data from abundance surveys. It is probable that, in these situations, the principal role of $\mathrm{RS}$ and GIS is to make prospective surveys more cost-effective (Hendrickx et al. 1999). In Burkina Faso a large grid-based baseline data survey, implemented in preparation for a control programme (L. Percoma, personal communication), deployed 3189 traps in an area of $40000 \mathrm{~km}^{2}$, and the data were used to develop a spatio-temporal model of African Animal Trypanosomosis (AAT) risk that was validated using parasitological data on cattle (Dicko et al. 2015; Feldmann et al., this volume). The model included the prediction of tsetse densities and their infection rate, and hence such predictions can be very useful to focus the control effort on disease transmission "hot spots".

\subsubsection{GIS for Decision Support}

Mapping pest distribution on a regional or national scale is an important first step in assessing the feasibility and spatial targeting of the SIT and other area-wide control actions. However, technical and resource constraints may make large-scale operations, over the whole of the identified area of potential pest distribution, to be impractical or uneconomic. Therefore, specific environmental information is required, 
either to identify parameters that are linked to pest presence, or to guide future sampling efforts to address specific questions including levels of genetic variability, similarity, and diversity among target insects.

Recently, the economic benefits to livestock keepers from intervening against AAT were mapped in eastern Africa (Shaw et al. 2014). The study was conducted for six tsetse-infested countries in eastern Africa: Ethiopia, Kenya, Somalia, South Sudan, Sudan, and Uganda. Cattle production systems were mapped, and herd models for each production system were developed, in the presence or absence of AAT. The differences in income between these two scenarios enabled the mapping of the maximum potential benefits that could be obtained from tsetse and trypanosomosis control. The potential benefits ranged from USD 500 per square kilometre to more than USD 10000 . Such models could be used to prioritize tsetse and trypanosomosis interventions on a regional scale when used in combination with other data layers, e.g. tsetse distribution and density. The models also accounted for possible restocking of livestock in neighbouring areas when maximum stocking rates were exceeded.

\subsubsection{Mapping Pest Density with a Large Spatial Resolution}

The spatial distribution of most insect pests is not uniform but patchy, and there can be localized pockets of high insect density, in spite of a potentially misleading lowoverall population density. It is of prime importance, for the development and implementation of an insect control programme, that these pockets or "hot spots" be located (Shiga 1991).

Depending on the spatial scale of the heterogeneity of insect density, the climate and remote-sensing datasets used to predict insect distribution over wide areas may not be appropriate for work on larger scales. AVHRR data, for example, have a native resolution of $1.1 \mathrm{~km}$, but are commonly resampled to derive images with $4 \times 4$ or $8 \times 8$ $\mathrm{km}$ pixels. However, several studies have successfully used high-resolution spatial data from Landsat and SPOT satellites to identify habitats associated with high insect density (Rejmankova et al. 1995; Roberts et al. 1996). For tsetse flies, fine-tuned studies of their habitat (type of vegetation and fragmentation level) at a high resolution (Landsat ETM+ data with a $30-\mathrm{m}$ resolution) successfully predicted their densities at a local scale in Zambia and Burkina Faso (Guerrini et al. 2008; Ducheyne et al. 2009). More recently, MODIS data (1-km resolution) were used to upscale these studies to a national level in Burkina Faso (Dicko et al. 2015).

Since the spatial distributions of insect populations are not constant, but tend to change over time, it is important that, where possible, risk maps be dynamic rather than static. For example, populations of riverine tsetse flies in West Africa commonly expand and contract seasonally along the river vegetation and perpendicular to the tributaries. The use of spatial analysis incorporating multi-temporal remote-sensing data enabled generating a "dynamic population distribution model" to predict these temporal and spatial population dynamics, and to link spatial patterns with heterogeneity of habitat (Dicko et al. 2015). This allows a more efficient and guided (rather than ad hoc) deployment of sampling devices during subsequent surveys, i.e. the sampling devices can be deployed in those areas where there is a high probability of trapping or, alternatively, in areas of low probability to confirm the model). The implication is that, assuming an adequate geo-spatial model exists, an efficient survey 
strategy can be developed largely from the office, and detailed implementation guidelines, regarding where, how, and when to deploy the sampling devices, can be elaborated for the field teams. This would not only ensure adequate sampling coverage in all ecosystems, but also prevent the deployment of too many sampling devices in unproductive or unrepresentative sites, unnecessarily increasing project costs (Bouyer et al. 2010).

The availability of temporal and spatial distribution models of the target insect populations on a large spatial scale has implications beyond the design of efficient sampling frames. In particular, such models can facilitate a more-efficient deployment of suppression tools and also a better-targeted release of sterile insects (Dicko et al. 2014). This would also enable simulating combinations of strategies like successive or simultaneous use of insecticide targets and the SIT to identify the most effective strategy (S. L. Peck, personal communication). This increased efficiency should also translate into considerable economic savings in terms of logistics, personnel and sterile insects.

\subsection{Development and Implementation of Appropriate Insect Suppression and Sterile Male Release Programmes}

\subsubsection{Selection of Appropriate Suppression Methods}

Since the release of sterile insects is only efficient when they sufficiently outnumber the native insects, the SIT is more cost-efficient with a reduced density of the target population (Dame 1971). The density of untreated insect populations is usually too high, and needs to be reduced prior to the mass-release of sterile insects. Depending on the target insect, a variety of pre-release population suppression methods are usually available (Mangan and Bouyer, this volume), but their usefulness, appropriateness, and effectiveness will be determined by the characteristics of each target area or local situation. Pending the availability of suitable data layers (demography, land use/land cover, vegetation classification, distribution of target insect, etc.), spatial analysis can assist with the decision to select the most appropriate suppression method for a given target zone. This is demonstrated by the following examples for the suppression of tsetse fly populations in AW-IPM programmes:

- Sequential Aerosol Technique (SAT). The SAT involves the application of nonresidual ultra-low-volume insecticides by fixed-wing aircraft or helicopter (or from vehicles using hot and cold fogging). The goal is to kill adult tsetse flies in the first spraying cycle by direct contact with insecticide droplets, and then kill emerging flies in five subsequent application cycles before the emerged flies can deposit larvae (Allsopp 1984). In view of the sensitivity and susceptibility of the SAT technique to topography, wind velocity and direction, temperature inversion, etc., a spatial analysis can provide information on the suitability of the target zone in terms of: (1) topography (the application of the SAT becomes problematic when the terrain becomes mountainous), (2) habitat and vegetation cover (correlation analysis between the vegetation density and the propensity of insecticide droplets to penetrate the tree canopy, to make predictions on the vertical dispersal rate of insecticide droplets in various vegetation types), and (3) 
wind velocity (using climatic models to predict the dispersal and distribution patterns of insecticide droplets in each particular situation). In the eradication programme against Glossina morsitans centralis in Botswana (Kgori et al. 2006), GIS not only enabled the close alignment of flight swaths to assure full coverage of the target population in the spraying areas, but were also used to develop the monitoring system that demonstrated the successful outcome of the project.

- Live-Bait Technology. In this technique, residual insecticides are applied to host animals that attract tsetse flies, which are killed on contact with the insecticide (Bauer et al. 1992). The technique is efficient and cost-effective, provided the density of the livestock population in the target area (if livestock is the main host) is sufficiently high. The distribution of animal herds is generally heterogeneous in space, and GIS can help identify areas where additional control tactics such as targets and traps are necessary to control the target population (Kagbadouno et al. 2011; Adam et al. 2013).

- Stationary-Bait Technology (insecticide-impregnated targets and traps). Tsetse populations can also be suppressed by deploying artificial stationary devices, which attract tsetse flies (Green 1994). The flies will be killed either upon making contact with the surface area of the target/trap (which is impregnated with a residual insecticide) (Laveissière et al. 1980) or when retained in a no-escape device (Dransfield et al. 1990). A spatial correlation analysis, using demographic data layers and tsetse population distribution models, can indicate how efficient or suitable this technology is in specific areas.

\subsubsection{Models to Predict Outcome of Different Suppression Scenarios}

Each area targeted for control will in most cases be heterogeneous, in terms of composition of the habitat (land use and land cover), vegetation cover and species composition, host (e.g. livestock and agricultural crops) distribution, demography, topography, etc., which will demand an integration of different suppression methods (Vreysen 2001; Mangan and Bouyer, this volume). Spatial analysis can be used to model the effect of various combinations of methods on the insect population, and assist in the decision to select the best combination (Kagbadouno et al. 2011; Adam et al. 2013).

\subsubsection{Implementation of Suppression and Sterile Male Release Programmes}

Aside from providing decision-support in the development and implementation of surveys, optimizing the suppression phase, and modelling the outcome of various suppression scenarios, GIS tools can assist in the actual implementation of suppression programmes, including sterile insect releases. A geo-spatial model, e.g. developed in the programme against G. p. gambiensis in Senegal to guide the distribution and density surveys, can be exploited to inform decisions on how a suppression strategy can be implemented. For example, spatial analysis can provide decision-support to select appropriate sites to deploy insecticide-impregnated traps and targets in tsetse suppression programmes, and ensure that the required target/trap density per surface unit is achieved with respect to vegetation type, topography, insect distribution, and other relevant factors (Fig. 3 and Box 2). 
(a)

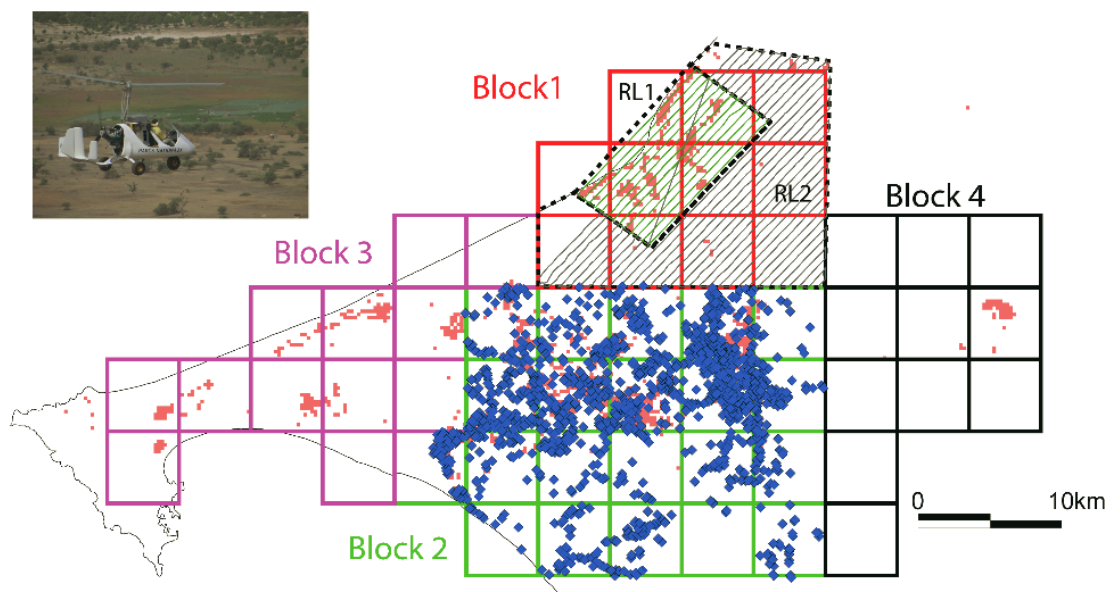

(b)

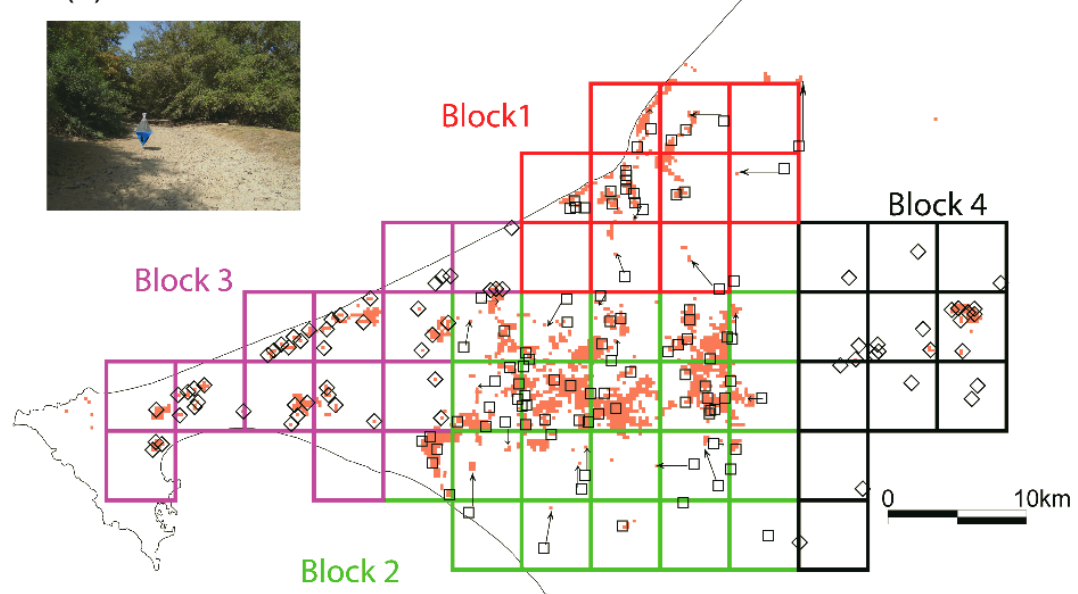

Figure 3. GIS and spatial modelling to optimize the tsetse eradication project in the Niayes region of Senegal. (a) Optimization of the integrated control strategy using model predictions. A MaxEnt model predicted suitable habitats for G. p. gambiensis (sensitivity 0.96, specificity 0.57). Block 1 - suitable habitats delimited two polygons for aerial releases (RL1 and RL2) where the minimum numbers of sterile males released per $\mathrm{km}^{2}$ were 24 and 11 , respectively. Chilled adult tsetse flies were released with a Mubarqui smart release machine in a gyrocopter (upper left) from the Kalahari aerodrome. Block 1 - green and grey lines show the track flying records on 14.04.2014 in RL1 and 11.04.2014 in RL2, respectively. Block 2 -for population suppression 1347 insecticide-impregnated traps were set from December 2012 to February 2013 in the predicted suitable sites (blue lozenges). (b) Optimization of the monitoring system (biconical traps, upper left) using MaxEnt model predictions. Blocks 1 and $2-23 \%$ of the traps

(black squares) deployed in the closest suitable patch. Blocks 3 and 4 (monitoring not yet started) - theoretical positions of the traps (black lozenges) suited to model predictions. Black arrows show displacements of traps following model predictions. (Modified from Dicko et al. 2014, reproduced with permission.) 


\section{Box 2. Past and Current Applications of GIS in Area-Wide Integrated Pest Management Programmes that Include the SIT}

The GIS/RS, as a decision-support tool in AW-IPM programmes integrating the release of sterile insects, has been used to spatially display data, and to plan, implement and evaluate programmes. AWIPM programmes using the SIT against fruit flies are among the most successful programmes against major insect pests, and these programmes rely on the advanced use of GIS. In programmes against the Mediterranean fruit fly Ceratitis capitata (Wiedemann), such as the programme in Argentina, the "Moscamed" programme in Guatemala/Mexico, and the prevention programmes in California and Florida (Enkerlin, this volume), GIS/GPS/RS are mainly used to:

- Provide navigational guidance in the release of the sterile insects, and to provide "real-time tracking" using commercially available satellite navigation/flight recorders.

- Map and visually display the various trapping sites and monitoring routes.

- Select trapping sites, using a grid layer over topographical maps or satellite imagery, and associating the trapping site with host and topographical features and their attributes.

In addition, the "Moscamed" programme in Guatemala/Mexico is using GIS as a major component of various studies on: (1) fly performance in relation to altitude, wind velocity, habitat, etc., (2) "hotspot" areas (where the pest persists over time despite intense efforts to suppress it), (3) insect behaviour in relation to the timing of release (afternoon, night, or morning), and (4) changes in the dispersal behaviour of sterile insects over time (P. Gomes, personal communication).

GIS/RS were also used in AW-IPM programmes against the New World screwworm Cochliomyia hominivorax (Coquerel). In Panama, GIS/RS were used to identify different vegetation types, and correlate the spatial and temporal distribution of screwworms with the various vegetation covers in a tropical environment. After classifying the forests based on tree height, structure, and species composition, the highest screwworm population density was found during the transition period from the wet to the dry season, and in forest habitats as opposed to open areas (Phillips et al. 2004). These data were used to more efficiently deploy monitoring tools in habitats favoured by screwworms, which could lead to earlier detection of low densities of screwworm populations, or possibly earlier control of outbreaks. The study clearly showed that GIS/RS can be used to improve trap placement by identifying areas of high screwworm activity. The method was applied in early 2003 to develop a trapping strategy after the accidental outbreak of the screwworm at the screwworm facility in Chiapas, Mexico (Phillips et al. 2004). Using GIS/RS techniques, optimal trapping sites were selected, which represented a reduction of $79 \%$ of the original trapping sites, i.e. considerable savings in terms of personnel and logistics.

A recent example of using GIS and spatial modelling for planning, implementing and evaluating an AW-IPM program with an SIT component is the tsetse eradication programme in Senegal. In this programme suitable tsetse habitat was identified using a supervised classification during the feasibility phase, which reduced by $94 \%$ the required sample area to identify the distribution limits of target populations (Bouyer et al. 2010). Thereafter, these technologies were used during the pre-operational phase to assess the survival, mortality, and competitiveness of sterile males during pilot release trials. Finally, the method to identify suitable habitats for G. p. gambiensis was optimized and improved by RS techniques that were based on a MaxEnt population distribution model (Dicko et al. 2014). Using this model the number of traps per $\mathrm{km}^{2}$ needed to suppress tsetse populations was reduced by $>95 \%$. The model was also used to determine the densities of sterile males to be released in the target area, i.e. 10 sterile males per $\mathrm{km}^{2}$ if the habitat was unsuitable, 100 sterile males per $\mathrm{km}^{2}$ if it was suitable. The releases were done using an automatic chilled-adult release device that was parameterized with the GIS during the flights. Finally, it improved the sensibility of the permanent monitoring system by locating the fixed monitoring sites in the most suitable places (Fig. 3). 
The uniform application of certain suppression measures (e.g. bait sprays for fruit flies, SAT for tsetse flies) over a heterogeneous pest distribution target area can have negative implications, both in terms of cost and environmental impact, since habitats may be contaminated by unnecessary applications of insecticide (Papadopoulos et al. 2003). Navigation/recording systems (such as Trimble's TrimFlight 3 Ag-GPS system or SATLOCK's AirStar system), which guarantee the correct application of the insecticides during aerial application, and ensure that fuel and materials are used efficiently, have been used for years in several fruit fly AW-IPM programmes that release sterile flies. Using these systems facilitates precise guidance, automated recording of covered areas (maximum efficiency, minimum overlap, and skips (omission of areas), identification and remedy of skips before leaving the operational area (avoiding costly call-backs), waypoint navigation, mapping capabilities, and control of insecticide-flow and sterile insect release rates (depending on pest distribution and density) based on ground speed. This eliminates the need for timeconsuming and costly ground markers, such as beacons or flaggers. The system is compatible with a wide range of GIS software packages, and enables applications to have better than 1-m accuracy.

In many programmes that include the release of sterile insects, these are released at a constant dispersal rate (i.e. a uniform density per surface unit). As a consequence, insufficient overflooding ratios might result in areas of high native-insect population density, whereas more sterile insects than necessary might be released in areas of low native-insect population density (Vreysen, this volume). GIS and spatial analysis can provide guidance on spatial sterile insect requirements and dispersal patterns, in relation to wild insect population densities, habitat, elevation, etc. in a dynamic way (i.e. data layers on the target insect distribution are updated regularly or spatiotemporal models of insect densities are used (Dicko et al. 2015)). This will result in a much more efficient use of sterile insects. In addition, commercially available satellite navigation/flight recorder systems, e.g. Ag-Nav, provide real-time tracking, and can visually display the areas that were treated with sterile insects (or have been left out), and at which altitude insects were released (to ensure a proper spread). This permits proper feedback to programme managers (Dowell et al., this volume).

An example of a new automatic release system is the Macx System (Mubarqui group); it has been used routinely in fruit fly control programmes. It is linked to GIS software installed on tablets on board the aircraft. These systems ensure an efficient use of the sterile insects available as they automatically start and stop the releases of sterile males when entering or leaving the release areas (Fig. 4a), but also because they can adapt the sterile male release density to that of certain vegetation types, topography or density of the wild populations (Mubarqui et al. 2014). (For example, in Valencia, Spain, the rate of releasing sterile Mediterranean fruit flies is automatically adjusted according to the ripening period of citrus varieties in the target area (R. Argilés Herrero, personal communication)). The software provides automatic reports of the flights by uploading the data to an online relational database once the aircraft is back at the airport, or even in real time using a Global System for Mobile Communications (GSM) connection. 
(a)

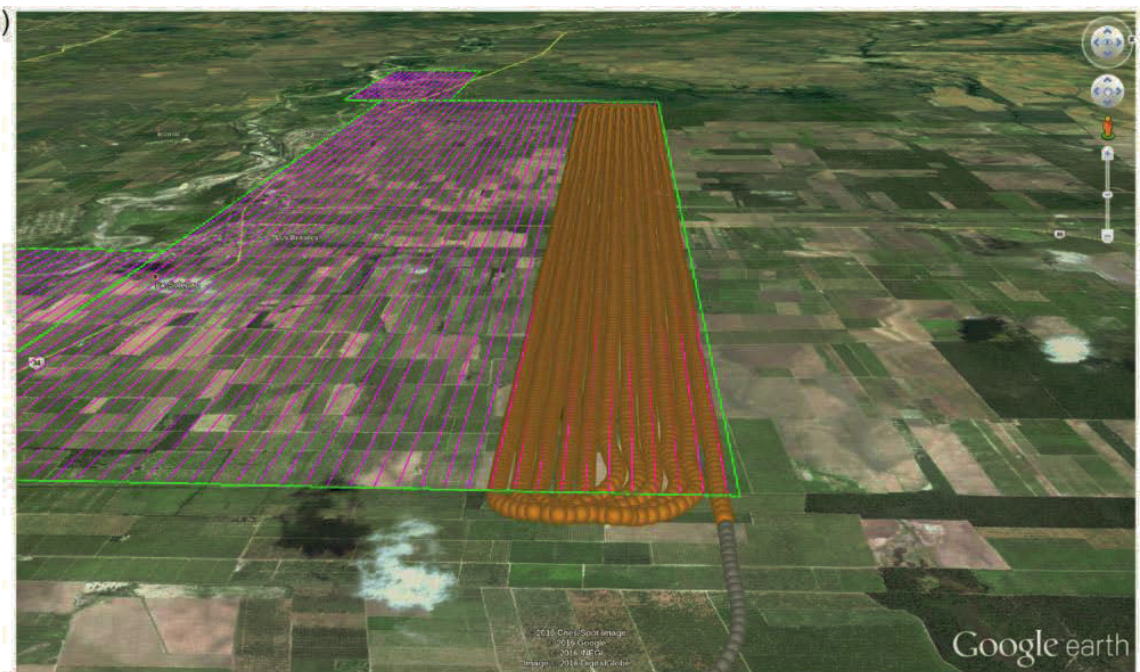

(b)

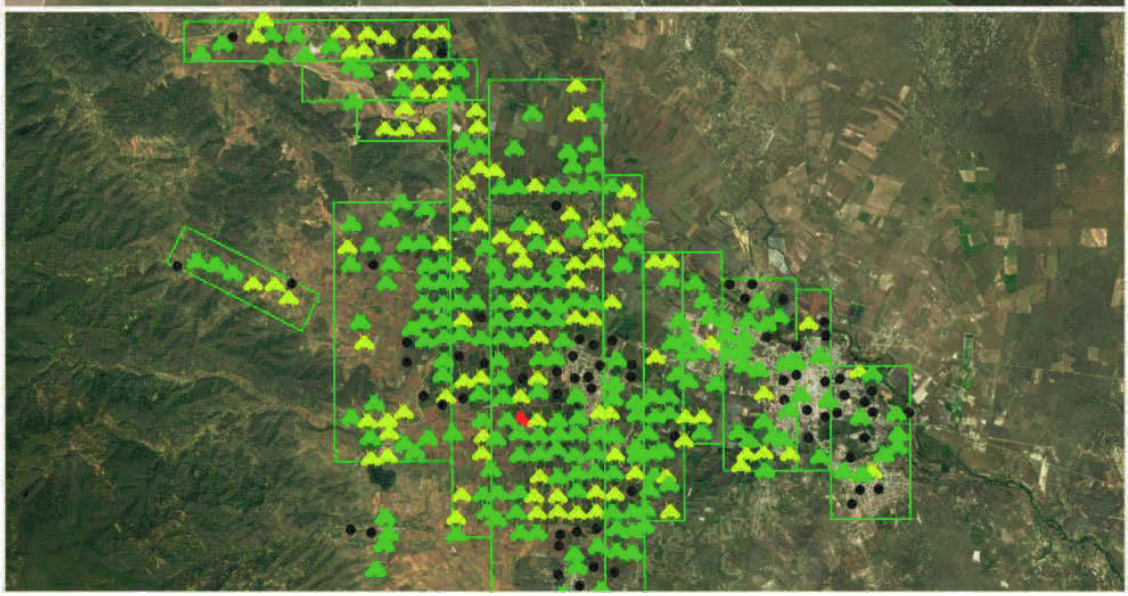

Figure 4. Optimization of area-wide fruit fly control in Mexico using the Macx System. (a) Parametrization of the sterile male releases of Anastrepha ludens (Loew) near Padilla, Tamps, on 10 July 2016. Release polygons are shown as green rectangles, theoretical release lines as pink lines, and tracks of the actual flying/release lines as orange-coloured spheres. (b) Monitoring results of A. ludens on week 28 of 2016 near Rio Verde, San Luis Potosí. Release polygons are shown as green rectangles, traps with catches of only sterile males as symbolic green flies, traps with catches of mixed sterile and wild males as yellow flies, traps with catches of only wild males as red flies, and traps without captures as black circles. (Reproduced with the permission of the Mubarqui group.) 


\subsection{Monitoring Suppression or Release Programmes}

Monitoring is an essential component of any AW-IPM programme (Vreysen, this volume). However, monitoring is time-consuming, and requires considerable funds for materials, logistics, and personnel. A careful balance must be found between "cost-efficiency" and collecting "reliable data". In most AW-IPM programmes, in view of the size of the target areas, monitoring (direct and indirect) must be restricted to carefully selected representative sites. Spatial analysis can assist in identifying and selecting appropriate reference or fixed monitoring sites (FMS). The concept of FMS was developed and used during the monitoring activities of the AW-IPM programme in Zanzibar, Tanzania, against the tsetse fly Glossina austeni Newstead, albeit without any GIS support (Vreysen et al. 2000; Vreysen, this volume), and was also used in the eradication programme of G. p. gambiensis in Senegal (Box 2).

From a pragmatic standpoint, it is important that all avenues of increasing the efficiency of trap-based monitoring systems are explored. Technologies that assist in the rapid transfer of data from the field to GIS are a key element of such systems. For example, in the codling moth AW-IPM programme in British Columbia, Canada, a GIS-based system is used to monitor a network of georeferenced traps. A bar-coding system is employed, in which the time and date that traps are monitored is automatically recorded, along with data on trap catch entered manually during a trap check (Dyck et al. 1993). These data can then be uploaded to the main project database via modem, facilitating the rapid output of electronic maps showing trap data.

Area-wide pest control activities can also use geostatistical analysis routines to get "better value" out of available trap data. A range of spatial analysis techniques, employing both geostatistics and GIS, may be valuable for analysing insect population processes at a landscape scale (Liebhold et al. 1993). Of these, one possible analytical technique is "kriging" — an interpolation procedure that relies on an autocorrelation function (the variogram) to provide weighting of nearby points used in the estimates. Kriging is ideally suited to the analysis of trap data, with interpolated output taking the form of contour maps or density surfaces of insect densities.

Such an approach has been used to monitor and predict populations of the spruce budworm Choristoneura fumiferana (Clemens), an important defoliator of trees in boreal forests in North America. Using kriging as a basis, Lyons et al. (2002) developed a set of software tools to produce interpolated estimates, using data from a pheromone-trapping network covering much of Canada and north-eastern USA. Output from the software system can be reclassified in a variety of ways, using GIS to provide maps that address particular management concerns. For example, maps are routinely produced that display areas where moth densities exceed a critical threshold, and hence where conventional larval sampling activities need to be initiated. Changeanalysis approaches are also used to create difference maps for consecutive years which, when reclassified, highlight areas of increasing, decreasing and stable moth populations. Kriged map surfaces have also been used as variables which, when combined with historical data on defoliation and defoliation frequency, have been used to successfully predict levels of defoliation in the following year. 
In the wider context of commercial crop decision-making, this type of approach has been taken a step further. In several states in the USA, integrated systems of insect and weather monitoring have been developed, providing estimates of insect and disease risk in near real-time. These systems, described by Thomas et al. (2002), use a network of georeferenced automated weather stations, which utilize radio telemetry to send data - on temperature, relative humidity, precipitation, and other meteorological parameters - every 15 minutes to a central processing centre. These data form the basis of Internet-based, daily estimates of weather and disease-risk related parameters (including insect degree-day maps), in addition to risk maps for specific diseases such as powdery mildew and Botrytis spp.

Another example of the use of GIS for monitoring is the Moscamed Programme in Mexico. This successful containment programme includes a trapping network of 24760 georeferenced traps (14 710 in Chiapas and 10050 in the rest of the Mexican States) (Enkerlin et al. 2015). Data of adult captures, including sterile and wild flies, enable the assessment of relative population density and ratio of sterile to wild males in space and time (Fig. 4b). A new system called "sabueso" has recently been developed by the Mubarqui group in Mexico, which represents a relevant advance in technology for capturing the information from the field in real-time from the trapping network. The system is installed in low-cost smartphones, and allows the monitoring teams who are seeking the larvae and outbreaks to report their observations in realtime to the team in charge of mechanical control. The same information is available in maps similar to Fig. 4b, enabling easy queries and analyses by management teams while optimizing economical and human resources.

\subsection{Data Analysis}

Area-wide insect pest control programmes generate a large amount of entomological and other related data, not only during baseline data collection and feasibility surveys but also during the monitoring of suppression and release activities (Dyck, Reyes Flores et al., this volume; Vreysen, this volume). It is a real challenge to manage data efficiently, analyse and interpret the results in a timely manner, and provide programme managers with consolidated data in a suitable format. The GIS unit of any pest control programme, if linked to a relational database, provides an ideal medium for the storage and analysis of data, and it can greatly facilitate their interpretation. Adequate feedback to programme managers is a prerequisite for sound decisionmaking. The complexity and diversity of data accumulated during a control programme, requiring proper spatial analysis, are typified in the following examples:

- Data derived from initial surveys.

Temporal and spatial fluctuations in:

- Population distribution (immature and adult stages)

- Population density

- Population structure (composition -- immature and adult stages)

- Disease prevalence or infestation level in hosts.

- Data derived from monitoring suppression activities.

- Temporal and spatial changes in population distribution due to the application of the suppression methods 
- Temporal decline in the density of the target pest population in relation to different ecosystems

- Temporal changes in population structure (due to increase in mortality rates) in relation to different ecosystems.

- Data derived from monitoring sterile insect releases.

- Spatial and temporal fluctuations in the ratio of sterile to wild insects

- Spatial and temporal fluctuations in the rate of induced sterility in the native insect population.

Spatial correlation analysis using these variables will contribute to modelling the competitiveness of released insects in relation to habitat, host abundance/distribution, climatic variables, etc. Obtaining spatial and temporal data on sterile insect competitiveness is one of the most important features of any AW-IPM programme that releases sterile insects.

- Spatial and temporal fluctuations in the recapture rate of insects in traps, damage to hosts, disease patterns, etc.

These data can be correlated with the release rate of sterile insects over the release grids, and then models developed on the mobility, dispersal characteristics (Vreysen et al. 2013), and spatial occupation of the sterile insects in different vegetation types, etc. It can also be used to assess whether sterile males are aggregating in the same ecological niches as wild males -- to ensure appropriate sterile to wild male ratios throughout the control area (Vreysen et al. 2011).

The results of a spatial analysis of a suppression and release programme can provide answers on issues such as the adequacy of deployment of suppression devices (sufficient number, adequacy of spread, efficiency, level of damage, timeliness of replacement of the suppression methods, etc.), and the appropriateness of sterile insect release operations (e.g. coverage of the proper block, flight at the proper altitude, possibility that insects were blown into nearby bodies of water, influence of wind, delivery of sterile insects so that they find and concentrate at the same locations as wild insects, etc.). They can also be used to implement spatio-temporal models that enable the testing of various control scenarios and then using the most appropriate one (S. L. Peck, personal communication).

\subsection{Support for Sterile Insect Quality Control}

Frequent monitoring of the performance of sterile insects (i.e. insect quality) in the field is an important, although often neglected, component of AW-IPM programmes that integrate the SIT (FAO/IAEA/USDA 2019). Parameters such as survival, mobility, dispersal characteristics, and spatial occupation of the habitat significantly influence the field performance or the competitiveness of released insects (Lance and McInnis, this volume; Parker, Vreysen et al., this volume; Vreysen, this volume). The values of these parameters may change over time, and are affected by host availability, vegetation cover, vegetation species, altitude, etc. GIS and spatial modelling can be used to predict these temporal and spatial changes in insect quality, and thus assist in developing remedies and timely adjustments in an intervention programme. As an example, swaths of flight release lanes are inherently linked to the dispersal capacity and mobility of the released insects, whereas their average survival 
determines the release frequency (Hendrichs, Vreysen et al., this volume). Models can be developed to correlate sterile insect survival with host availability, vegetation cover, etc. to assist in regularly adjusting the dispersal rate of insects in relation to space (e.g. more frequent releases in those areas where survival is low). In addition, a spatial and temporal analysis of the dispersal characteristics offers opportunities to assess whether this parameter is changing with the length of time that the insects have been colonized in the rearing facility (Parker, Mamai et al., this volume).

There is great potential for GIS to support the assessment of the quality control of released insects, particularly with regard to: (1) comparing the performance (competitiveness, mobility, dispersal, survival) of sterile insects derived from different strains, (2) studying the effects of releasing flies using different release systems, or at different altitudes, over different topographies (e.g. canyons), at different wind velocities, etc., and (3) analysing hot spots or reservoir areas where the pest persists in spite of intense actions to suppress the population.

\subsection{Barriers to Using GIS}

After the 1990's GIS became more available and accessible to the general public, and the further development and diffusion of GIS have made available a large amount of information from different sources. The cost of acquiring primary data (such as satellite remote-sensing data) has decreased considerably, and many satellite data are now freely available on the Internet. RS images and derivative products (vegetation indices, rainfall indices, etc.) are now available at different levels of geometric preprocessing, thus facilitating their use by non-experts.

Today, the barriers to successful GIS development are significantly lower than they were in the past. The costs of hardware are now relatively low, while most software and data are free. Perhaps most significantly, GIS software is becoming increasingly accessible to non-specialists; non-geographers, after receiving appropriate training, can now carry out many GIS procedures without specialist support (although this does not completely eliminate the need for expert input; note comments below under "GIS expertise").

These advances, however, do not mean that potential barriers or pitfalls no longer exist. Several considerations need special attention, particularly when working in the context of a developing country, if a GIS endeavour is to be successful (BESR 2002). These considerations include:

- Technical limitations. Limits in the accessibility of spatial data, such as inadequate telecommunications infrastructure, limited bandwidth or data storage capacities, and low Internet connectivity in certain countries, may hamper efforts to rapidly process and output GIS data.

- GIS expertise. Trained and experienced experts in GIS are often in rather short supply, particularly in developing countries. The increasing accessibility of GIS software does not obviate the need for input from appropriately trained operators. Technical issues around data capture and integration can be non-trivial, as are procedures for image processing. Decisions regarding accuracy and permissible levels of data generalization also require relevant experience on the part of the GIS operator. 
- Maintaining consistency. In many instances, AW-IPM programmes are implemented over large geographical areas, i.e. on a national or regional scale, employing various field teams in a series of sub-programmes, each attached to a particular country, zone or region. Agreements must be reached on compatible GIS formats, standardized methods of data collection, and data resources. These need to be kept consistent throughout the life of a project.

- Administrative challenges. It can be a real challenge to easily gain access to available data because of unawareness about data request procedures on the part of government officials, complicated protocols for requesting government data, a variety of data standards making the sharing of data difficult, and complications due to copyright and distribution issues.

- Pre-processing GIS and RS data. This step is often the most time-consuming task in any project involving such data. Based on the data considered in the analysis and particularly for RS data, some pre-processing steps must be applied to make the data usable for further analysis. The most common pre-processing methods for RS data are corrections (radiometric and geometric corrections) that seek to minimize distortion caused by satellite sensors. Furthermore, image enhancement methods such as noise removal or filtering may also be applied to RS data prior to the analysis. Finally, other operations such as georeferencing and mosaicking (combining multiple images) can also be used before analysis.

It is important that, at all stages of GIS development, a dialogue between those responsible for designing and maintaining a GIS system, and those whose principal interest is the output of the system, begins at the start of the planning process, and continues throughout the life of a project. GIS operators need to realize that many decision-makers, in developed and developing countries, have no experience with GIS and other spatial decision-support tools, and thus do not appreciate the potential in using geographic information, or the technical issues involved in setting up and maintaining GIS.

In this context, one essential message must be conveyed - the development of GIS requires careful planning, and often a substantial time-commitment. In a previous section (2.1.) of this chapter, GIS were defined as systems for capturing, cleaning, integrating, storing, retrieving, analysing, and displaying mapped information and data. These functions can be broadly seen as a series of operations that describes the data stream from the original source to a final map or output. The initial stages of this process (up to the point of storing the data) can be extremely time-consuming, and therefore it is important that GIS are designed to meet the needs of the various end users, and to include as little redundant information as possible. Once data have been integrated into GIS, it is possible to perform a wide range of spatial analyses on them at very little cost.

\section{CONCLUSIONS}

In ecology and epidemiology, GIS, GPS, RS, and spatial modelling are increasingly used as a complementary set of spatial tools for project planning, implementation, and evaluation. A GIS-centred approach offers many potential advantages to the areawide application of the SIT and other control methods, as a decision-support tool in 
the day-to-day management of AW-IPM programmes. In the past, GIS have been applied mainly by academics as an end in itself, or at best as a research tool analysing correlations between different parameters to select priority areas where pest elimination would result in the highest socio-economic impact. More recently, GIS have been used as a tool for planning, implementing, optimizing, and evaluating SITbased operations.

GIS also facilitate the overlaying of a variety of data coverages, e.g. climate, land use, drainage, etc., to identify factors that may explain the spatial and temporal patterns of insects and/or diseases. Using appropriate spatial analytical approaches, GIS can be used to identify and map the habitat of insect species and their relationship to cropping areas or human and animal populations. In this way, it is possible to generate maps indicating the risk of pests or diseases on a variety of spatial scales, and to monitor, in space and time, integrated information on insect population dynamics, ecological and meteorological conditions, and the incidence of disease or crop damage.

AW-IPM programmes that include the release of sterile insects are, because of the interdependence of their many linked components, inherently complex; the collapse of one component might jeopardize the successful outcome of the entire programme. The success of such a programme depends mainly on aspects related to: (1) the quality of the sterile insect (e.g. sexual competitiveness of the irradiated and released insects, survival, mobility, dispersal characteristics, etc.), (2) the management of the release programme (e.g. timely delivery of insects, appropriate placement of the insects in the natural habitat, uninterrupted supply of sufficient sterile insects, etc.) (Dowell et al., this volume), and (3) the implementation of related programme components (e.g. adequate suppression of the native-insect population, relevant public relation campaigns, ample collaboration with the livestock/crop industry and other stakeholders, etc.) (Dyck, Regidor Fernández et al., this volume; Mangan and Bouyer, this volume). Programme managers need to keep a comprehensive overview of all these essential programme components and their outcomes, almost on a daily basis, and GIS provide an ideal tool to analyse and display data from these multifaceted programmes. Close collaboration between programme entomologists, and SIT and GIS experts and modellers, will be a prerequisite to fully exploit the potential of GIS and spatial modelling as decision-support tools, and to render AW-IPM programmes using the SIT much more efficient and cost-effective.

To make GIS/RS more applicable, programme managers must get access to all available data layers (administrative boundaries, soil types, crops, meteorological data, satellite imagery, vegetation cover, etc.). GIS technicians and modellers can, in many instances, produce data layers that are not available or are missing, e.g. by digitizing topographical maps and implementing supervised classification to map the landscape cover or even insect distribution models. Also, the establishment of global networks to enhance research collaboration, data sharing, and the pooling of common resources, e.g. via the development of special websites, can greatly facilitate the development potential of GIS. Regarding the day-to-day implementation of the various programme components, all data sets on the target insect (survey data, monitoring data, etc.) and related aspects (crop damage, disease incidence, etc.) must be georeferenced and entered into relational databases that are compatible with, and 
can easily be linked to, GIS software (e.g. using ACCESS-based databases rather than EXCEL spreadsheets), allowing straightforward summaries and queries. Finally, standardized data collection, continuous flow of data files to a central location, and increased understanding of the basics of GIS by programme managers, are additional prerequisites to exploit GIS to their full potential in AW-IPM programmes.

\section{REFERENCES}

Adam, Y., G. Cecchi, P. M. Kgori, T. Marcotty, C. I. Mahama, M. Abavana, B. Anderson, M. Paone, R. Mattioli, and J. Bouyer. 2013. The sequential aerosol technique: a major component in an integrated strategy of intervention against riverine tsetse in Ghana. PLOS Neglected Tropical Diseases 7(3): e2135. https://doi.org/10.1371/journal.pntd.0002135

Allsopp, R. 1984. Control of tsetse flies (Diptera: Glossinidae) using insecticides: a review and future prospects. Bulletin of Entomological Research 74: 1-23. https://doi.org/10.1017/S0007485300009895

Anyamba, A., J. L. Small, C. J. Tucker, and E. W. Pak. 2014. Thirty-two years of Sahelian zone growing season non-stationary NDVI3g patterns and trends. Remote Sensing 6: 3101-3122. DOI: $10.3390 / \mathrm{rs} 6043101$ http://www.mdpi.com/2072-4292/6/4/3101

Barnes, J. M., R. Trinidad-Correa, T. V. Orum, R. Felix-Gastelum, and M. R. Nelson. 1999. Landscape ecology as a new infrastructure for improved management of plant viruses and their insect vectors in agroecosystems. Ecosystem Health 5: 26-35.

https://doi.org/10.1046/j.1526-0992.1999.09904.x

Bauer, B., I. Kaboré, A. Liebisch, F. Meyer, and J. Petrich-Bauer. 1992. Simultaneous control of ticks and tsetse flies in Satiri, Burkina Faso, by the use of flumethrin pour on for cattle. Tropical Medicine and Parasitology 43(1): 41-46.

https://www.researchgate.net/publication/21556238_Simultaneous_control_of_ticks_and_tsetse_flies_i n_Satiri_Burkina_Faso_by_the_use_of_flumethrin_pour_on_for_cattle

Beck, L. R., B. M. Lobitz, and B. L. Wood. 2000. Remote sensing and human health: new sensors and new opportunities. Emerging Infectious Diseases 6: 217-227. https://wwwnc.cdc.gov/eid/article/6/3/00-0301_article

(BESR) Board on Earth Sciences and Resources. 2002. Down to earth: geographical information for sustainable development in Africa. The National Academies Press, Washington, DC, USA. http://www.nap.edu/books/0309084784/html

Bivand, R., E. Pebesma, and V. Gómez-Rubio. 2008. Applied spatial data analysis with R. Springer, New York, NY, USA.

Bonham-Carter, G. F. 1994. Geographical information systems for geoscientists. Pergamon, NY, USA.

Bouyer, J., M. T. Seck, B. Sall, E. Y. Ndiaye, L. Guerrini, and M. J. B. Vreysen. 2010. Stratified entomological sampling in preparation of an area-wide integrated pest management program: the example of Glossina palpalis gambiensis (Diptera: Glossinidae) in the Niayes of Senegal. Journal of Medical Entomology 47: 543-552. https://doi.org/10.1093/jmedent/47.4.543

Bouyer, J., A. H. Dicko, G. Cecchi, S. Ravel, L. Guerrini, P. Solano, M. J. B. Vreysen, T. De Meeûs, and R. Lancelot. 2015. Mapping landscape friction to locate isolated tsetse populations that are candidates for elimination. Proceedings of the National Academy of Sciences of the United States of America 112: 14575-14580. http://www.pnas.org/content/112/47/14575.full.pdf

Brooker, S., and E. Michael. 2000. The potential of geographical information systems and remote sensing in the epidemiology and control of human helminth infections. Advances in Parasitology 47: $245-288$. https://doi.org/10.1016/S0065-308X(00)47011-9

Burrough, P. A., and R. A. McDonnell. 1998. Principles of geographic information systems. Oxford University Press, Oxford, UK.

Cecchi, G., and R. C. Mattioli. 2009. Geospatial datasets and analyses for an environmental approach to African trypanosomiasis. PAAT Technical and Scientific Series 9. FAO, Rome, Italy. http://www.fao.org/docrep/012/i0809e/i0809e00.htm

Clarke, K. C., S. L. McLafferty, and B. J. Tempalski. 1996. On epidemiology and geographic information systems: a review and discussion of future directions. Emerging Infectious Diseases 2: 8592. https://wwwnc.cdc.gov/eid/article/2/2/96-0202_article 
Dame, D. A. 1971. Control by sterilization of Glossina, pp. 533-542. In The African trypanosomiases. Geo. Allen and Unwin Ltd., London, UK.

Dicko, A. H., R. Lancelot, M. T. Seck, L. Guerrini, B. Sall, M. Lo, M. J. B. Vreysen, T. Lefrançois, W. M. Fonta, S. L. Peck, and J. Bouyer. 2014. Using species distribution models to optimize vector control in the framework of the tsetse eradication campaign in Senegal. Proc. Nat. Acad. Sciences of the USA 111: 10149-10154. http://www.pnas.org/content/111/28/10149.full.pdf

Dicko, A. H., L. Percoma, A. Sow, Y. Adam, C. Mahama, I. Sidibé, G.-K. Dayo, S. Thévenon, W. Fonta, S. Sanfo, A. Djiteye, E. Salou, V. Djohan, G. Cecchi, and J. Bouyer. 2015. A spatiotemporal model of African animal trypanosomosis risk. PLOS Neglected Tropical Diseases 9: e0003921. https://doi.org/10.1371/journal.pntd.0003921

Dransfield, R. D., R. Brightwell, C. Kyorku, and B. Williams. 1990. Control of tsetse fly (Diptera: Glossinidae) populations using traps at Nguruman, south-west Kenya. Bulletin of Entomological Research 80(3): 265-276. https://doi.org/10.1017/S000748530005046X

Ducheyne, E., C. Mweempwa, C. De Pus, H. Vernieuwe, R. De Deken, G. Hendrickx, and P. Van den Bossche. 2009. The impact of habitat fragmentation on tsetse abundance on the plateau of eastern Zambia. Preventive Veterinary Medicine 91: 11-18. DOI: 10.1016/j.prevetmed.2009.05.009 https://www.ncbi.nlm.nih.gov/pmc/articles/PMC2722901/

Dyck, V. A., S. H. Graham, and K. A. Bloem. 1993. Implementation of the sterile insect release programme to eradicate the codling moth Cydia pomonella (L.) (Lepidoptera: Olethreutidae) in British Columbia, Canada, pp. 285-297. In Proceedings: Management of Insect Pests: Nuclear and Related Molecular and Genetic Techniques. FAO/IAEA International Symposium, 19-23 October 1992, Vienna, Austria. STI/PUB/909. IAEA, Vienna, Austria.

https://www.iaea.org/publications/3782/management-of-insect-pests-nuclear-and-related-molecularand-genetic-techniques

Elith, J., S. J. Phillips, T. Hastie, M. Dudík, Y. E. Chee, and C. J. Yates. 2011. A statistical explanation of MaxEnt for ecologists. Diversity and Distributions 17: 43-57. http://onlinelibrary.wiley.com/doi/10.1111/j.1472-4642.2010.00725.x/epdf

Enkerlin, W., J. M. Gutiérrez-Ruelas, A. V. Cortes, E. C. Roldan, D. Midgarden, E. Lira, J. L. Z. López, J. Hendrichs, P. Liedo, and F. J. T. Arriaga. 2015. Area freedom in Mexico from Mediterranean fruit fly (Diptera: Tephritidae): a review of over 30 years of a successful containment program using an integrated area-wide SIT approach. Florida Entomologist 98: 665-681. https://www.jstor.org/stable/24587698

(FAO/IAEA) Food and Agriculture Organization of the United Nations/International Atomic Energy Agency. 2006. Designing and implementing a geographical information system. A guide for managers of area-wide pest management programmes. IAEA, Vienna, Austria. http://www-naweb.iaea.org/nafa/ipc/public/ipc-gismanual-web.pdf

(FAO/IAEA/USDA) Food and Agriculture Organization of the United Nations/International Atomic Energy Agency/United States Department of Agriculture. 2019. Product quality control for sterile mass-reared and released tephritid fruit flies. Version 7.0. IAEA, Vienna, Austria. https://www.iaea.org/sites/default/files/qcv7.pdf

Green, C. H. 1994. Bait methods for tsetse fly control. Advances in Parasitology 34: 229-291. https://doi.org/10.1016/S0065-308X(08)60140-2

Guerrini, L., J. P. Bord, E. Ducheyne, and J. Bouyer. 2008. Fragmentation analysis for prediction of suitable habitat for vectors: example of riverine tsetse flies in Burkina Faso. Journal of Medical Entomology 45: 1180-1186. https://doi.org/10.1093/jmedent/45.6.1180

Guerrini, L., I. Sidibé, and J. Bouyer. 2009. Tsetse distribution in the Mouhoun River basin (Burkina Faso): the role of global and local geospatial datasets, pp. 41-52. In FAO (ed.), Geospatial datasets and analyses for an environmental approach to African trypanosomiasis. Section 2. PAAT Technical and Scientific Series 9. FAO, Rome, Italy. http://www.fao.org/docrep/012/i0809e/i0809e00.htm

Hartemink, N., S. O. Vanwambeke, H. Heesterbeek, D. Rogers, D. Morley, B. Pesson, C. Davies, S. Mahamdallie, and P. Ready. 2011. Integrated mapping of establishment risk for emerging vectorborne infections: a case study of canine leishmaniasis in southwest France. PLOS ONE 6(8): e20817. https://doi.org/10.1371/journal.pone.0020817

Hay, S. I., C. J. Tucker, D. J. Rogers, and M. J. Packer. 1996. Remotely sensed surrogates of meteorological data for the study of the distribution and abundance of arthropod vectors of disease. Annals of Tropical Medicine and Parasitology 90: 1-19. https://doi.org/10.1080/00034983.1996.11813021 
Hay, S. I., R. W. Snow, and D. J. Rogers. 1998. Predicting malaria seasons in Kenya using multitemporal meteorological satellite sensor data. Transactions of the Royal Society of Tropical Medicine and Hygiene 92: 12-20. https://doi.org/10.1016/S0035-9203(98)90936-1

Hay, S. I., A. J. Tatem, A. J. Graham, S. J. Goetz, and D. J. Rogers. 2006. Global environmental data for mapping infectious disease distribution. Advances in Parasitology 62: 37-77. https://doi.org/10.1016/S0065-308X(05)62002-7

Hendrickx, G., A. Napala, D. Rogers, P. Bastiaensen, and J. Slingenbergh. 1999. Can remotely sensed meteorological data significantly contribute to reduce costs of tsetse surveys? Memórias do Instituto Oswaldo Cruz 94(2): 273-276. http://dx.doi.org/10.1590/S0074-02761999000200028

Hendrickx, G., A. Napala, J. H. W. Slingenbergh, R. De Deken, and D. J. Rogers. 2001. A contribution towards simplifying area-wide tsetse surveys using medium resolution meteorological satellite data. Bulletin of Entomological Research 91: 333-346. https://doi.org/10.1079/BER2001103

Holmes, P. H. 1997. New approaches to the integrated control of trypanosomosis. Veterinary Parasitology 71(2-3): 121-135. https://doi.org/10.1016/S0304-4017(97)00026-5

Hutchinson, M. F., H. A. Nix, J. P. McMahon, and K. D. Ord. 1995. Africa - a topographic and climatic database. Centre for Resource and Environmental Studies, Australian National University, Canberra, Australia.

Kagbadouno, M. S., M. Camara, J. Bouyer, F. Courtin, M. F. Onikoyamou, C. J. Schofield, and P. Solano. 2011. Progress towards the eradication of tsetse from the Loos islands, Guinea. Parasites and Vectors 4: 18. https://doi.org/10.1186/1756-3305-4-18

Kgori, P. M., S. Modo, and S. J. Torr. 2006. The use of aerial spraying to eliminate tsetse from the Okavango Delta of Botswana. Acta Tropica 99: 184-199. https://doi.org/10.1016/j.actatropica.2006.07.007

Kitron, U. 1998. Landscape ecology and epidemiology of vector-borne diseases: tools for spatial analysis. Journal of Medical Entomology 35: 435-445. https://doi.org/10.1093/jmedent/35.4.435

Laveissière, C., D. Couret, and J. P. Kiénon. 1980. Lutte contre les glossines rivéraines à l'aide de pièges biconiques imprégnés d'insecticide en zone de savane humide. Résultats quantitatifs obtenus lors des premiers essais. Cahiers d'ORSTOM, Série Entomologie Médicale et Parasitologie 3: 209221.

Liebhold, A. M., R. E. Rossi, and W. P. Kemp. 1993. Geostatistics and geographic information systems in applied insect ecology. Annual Review of Entomology 38: 303-327. https://doi.org/10.1146/annurev.en.38.010193.001511

Liebhold, A., E. Luzader, R. Reardon, A. Roberts, F. W. Ravlin, A. Sharov, and G. Zhou. 1998. Forecasting gypsy moth (Lepidoptera: Lymantriidae) defoliation with a geographical information system. Journal of Economic Entomology 91: 464-472. https://doi.org/10.1093/jee/91.2.464

Linthicum, K. J., C. L. Bailey, F. G. Davies, and C. J. Tucker. 1987. Detection of Rift Valley fever viral activity in Kenya by satellite remote sensing imagery. Science 235(4796): 1656-1659. DOI: 10.1126/science.3823909 http://science.sciencemag.org/content/235/4796/1656

Linthicum, K. J., C. L. Bailey, C. J. Tucker, K. D. Mitchell, T. M. Logan, F. G. Davies, C. W. Kamau, P. C. Thande, and J. N. Wagateh. 1990. Application of polar-orbiting, meteorological satellite data to detect flooding of Rift Valley Fever virus vector mosquito habitats in Kenya. Medical and Veterinary Entomology 4: 433-438. http://onlinelibrary.wiley.com/doi/10.1111/j.1365-2915.1990.tb00462.x/abstract

Linthicum, K. J., A. Anyamba, C. J. Tucker, P. W.Kelley, M. F. Myers, and C. J. Peters. 1999. Climate and satellite indicators to forecast Rift Valley fever epidemics in Kenya. Science 285(5426): 397-400. DOI: 10.1126/science.285.5426.397 http://science.sciencemag.org/content/285/5426/397

Lyons, D. B., C. J. Sanders, and G. C. Jones. 2002. The use of geostatistics and GIS as tools for analyzing pheromone trap data at a landscape level: an update. IOBC-WPRS Bulletin 25: 1-14.

Matawa, F., K. S. Murwira, and W. Shereni. 2013. Modelling the distribution of suitable Glossina spp. habitat in the north western parts of Zimbabwe using remote sensing and climate data. Geoinformatics and Geostatistics: An Overview S1: 016. DOI: 10.4172/2327-4581.S1-016 https://www.scitechnol.com/2327-4581/2327-4581-S1-016.pdf

Moiroux, N., A. S. Bio-Bangana, A. Djènontin, F. Chandre, V. Corbel, and H. Guis. 2013. Modelling the risk of being bitten by malaria vectors in a vector control area in southern Benin, West Africa. Parasites and Vectors 6: 71. https://doi.org/10.1186/1756-3305-6-71

Mubarqui, R. L., R. C. Perez, R. A. Kladt, J. L. Z. Lopez, A. Parker, M. T. Seck, B. Sall, and J. Bouyer. 2014. The smart aerial release machine, a universal system for applying the sterile insect technique. PLOS ONE 9(7): e103077. https://doi.org/10.1371/journal.pone.0103077 
Nicolas, G., T. P. Robinson, G. R. W. Wint, G. Conchedda, G. Cinardi, and M. Gilbert. 2016. Using random forest to improve the downscaling of global livestock census data. PLOS ONE 11(3): e0150424. https://doi.org/10.1371/journal.pone.0150424

Nutter, F. W., R. R. Rubsam, S. E. Taylor, J. A. Harri, and P. D. Esker. 2002. Use of geospatiallyreferenced disease and weather data to improve site-specific forecasts for Stewart's disease of corn in the US corn belt. Computers and Electronics in Agriculture 37: 7-14.

https://doi.org/10.1016/S0168-1699(02)00112-6

Papadopoulos, N. T., B. I. Katsoyannos, and D. Nestel. 2003. Spatial autocorrelation analysis of a Ceratitis capitata (Diptera: Tephritidae) adult population in a mixed deciduous fruit orchard in northern Greece. Environmental Entomology 32: 319-326. https://doi.org/10.1603/0046-225X-32.2.319

Peck, S. L. 2012. Networks of habitat patches in tsetse fly control: implications of metapopulation structure on assessing local extinction probabilities. Ecological Modelling 246: 99-102. https://doi.org/10.1016/j.ecolmodel.2012.07.016

Peck, S. L., and J. Bouyer. 2012. Mathematical modelling, spatial complexity, and critical decisions in tsetse control. Journal of Economic Entomology 105: 1477-1486. https://doi.org/10.1603/EC12067

Pfeiffer, D. U., and M. Hugh-Jones. 2002. Geographical information systems as a tool in epidemiological assessment and wildlife disease management. Revue Scientifique et Technique de l'Office International des Epizooties 21: 91-102. http://www.oie.int/doc/ged/D525.PDF

Phillips, P. L., J. B. Welch, and M. Kramer. 2004. Seasonal and spatial distributions of adult screwworms (Diptera: Calliphoridae) in the Panama Canal area, Republic of Panama. Journal of Medical Entomology 41: 121-129. https://doi.org/10.1603/0022-2585-41.1.121

Pope, K. O., E. Rejmankova, H. M. Savage, J. I. Arredondo-Jimenez, M. H. Rodriguez, and D. R. Roberts. 1994. Remote sensing of tropical wetlands for malaria control in Chiapas, Mexico. Ecological Applications 4: 81-90. https://doi.org/10.2307/1942117

Randolph, S. E. 2000. Ticks and tick-borne disease systems in space and from space. Advances in Parasitology 47: 217-243. https://doi.org/10.1016/S0065-308X(00)47010-7

Rejmankova, E., D. R. Roberts, A. Pawley, S. Manguin, and J. Polanco. 1995. Predictions of adult Anopheles albimanus densities in villages based on distances to remotely sensed larval habitats. The American Journal of Tropical Medicine and Hygiene 53(5): 482-488. https://doi.org/10.4269/ajtmh.1995.53.482

Roberts, D. R., J. F. Paris, S. Manguin, R. E. Harbach, R. Woodruff, E. Rejmankova, J. Polanco, B. Wullschleger, and L. J. Legters. 1996. Predictions of malaria vector distribution in Belize based on multispectral satellite data. The American Journal of Tropical Medicine and Hygiene 54(3): 304-308. https://doi.org/10.4269/ajtmh.1996.54.304

Robinson, T. P. 1998. Geographic information systems and the selection of priority areas for control of tsetse-transmitted trypanosomiasis in Africa. Parasitology Today 14(11): 457-461. https://doi.org/10.1016/S0169-4758(98)01336-2

Robinson, T., D. Rogers, and B. Williams. 1997. Mapping tsetse habitat suitability in the common fly belt of southern Africa using multivariate analysis of climate and remotely sensed data. Medical and Veterinary Entomology 11(3): 235-245. https://doi.org/10.1111/j.1365-2915.1997.tb00401.x

Robinson, T. P., R. S. Harris, J. S. Hopkins, and B. G. Williams. 2002. An example of decision support for trypanosomiasis control using a geographical information system in eastern Zambia. International Journal of Geographical Information Science 16: 345-360. https://doi.org/10.1080/13658810110095057

Rogers, D. J. 1991. Satellite imagery, tsetse and trypanosomiasis in Africa. Preventive Veterinary Medicine 11: 201-220. https://doi.org/10.1016/S0167-5877(05)80005-4

Rogers, D. J. 2006. Models for vectors and vector-borne diseases. Advances in Parasitology 62: 1-35. https://doi.org/10.1016/S0065-308X(05)62001-5

Rogers, D. J., and S. E. Randolph. 1986. Distribution and abundance of tsetse flies (Glossina spp.). Journal of Animal Ecology 55: 1007-1025. http://www.jstor.org/stable/4430

Rogers, D. J., and S. E. Randolph. 1991. Mortality rates and population density of tsetse flies correlated with satellite imagery. Nature 351: 739-741. https://www.nature.com/articles/351739a0

Rogers, D. J., and B. G. Williams. 1993. Monitoring trypanosomiasis in space and time. Parasitology 106(Suppl. 1): S77-S92. https://doi.org/10.1017/S0031182000086133

Rogers, D. J., S. I. Hay, and M. J. Packer. 1996. Predicting the distribution of tsetse flies in West Africa using temporal Fourier processed meteorological satellite data. Annals of Tropical Medicine and Parasitology 90(3): 225-241. https://doi.org/10.1080/00034983.1996.11813049 
Shaw, A. P. M., G. Cecchi, G. R. W. Wint, R. C. Mattioli, and T. P. Robinson. 2014. Mapping the economic benefits to livestock keepers from intervening against bovine trypanosomosis in eastern Africa. Preventive Veterinary Medicine 113: 197-210. http://www.fao.org/docrep/019/as289e/as289e.pdf

Shiga, M. 1991. Future prospect of eradication of fruit flies, pp. 126-136. In K. Kawasaki, O. Iwahashi and K. Y. Kaneshiro (eds.), Proceedings, Symposium: The International Symposium on the Biology and Control of Fruit Flies. The Food and Fertilizer Technology Center, The University of the Ryukyus, and The Okinawa Prefectural Government, 2-4 September 1991, Okinawa, Japan.

Stevens, F. R., A. E. Gaughan, C. Linard, and A. J. Tatem. 2015. Disaggregating census data for population mapping using random forests with remotely-sensed and ancillary data. PLOS ONE 10(2): e0107042. https://doi.org/10.1371/journal.pone.0107042

Thomas, C. S., P. W. Skinner, A. D. Fox, C. A. Greer, and W. D. Gubler. 2002. Utilization of GIS/GPS-based information technology in commercial crop decision making in California, Washington, Oregon, Idaho, and Arizona. Journal of Nematology 34: 200-206. http://journals.fcla.edu/jon/article/view/69406

Thomson, M. C., and S. J. Connor. 2000. Environmental information systems for the control of arthropod vectors of disease. Medical and Veterinary Entomology 14: 227-244. http://onlinelibrary.wiley.com/doi/10.1046/j.1365-2915.2000.00250.x/references

Tsafack, N., P. Menozzi, T. Brevault, V. Soti, M. Deconchat, and A. Ouin. 2013. Effects of landscape context and agricultural practices on the abundance of cotton bollworm Helicoverpa armigera in cotton fields: a case study in northern Benin. International Journal of Pest Management 59: 294-302. http://dx.doi.org/10.1080/09670874.2013.852270

Vreysen, M. J. B. 2001. Principles of area-wide integrated tsetse fly control using the sterile insect technique. Médecine Tropicale 61(4-5): 397-411. https://www.researchgate.net/publication/11554946_Principles_of_areawide_integrated_tsetse_fly_control_using_the_sterile_insect_technique

Vreysen, M. J. B., K. M. Saleh, M. Y. Ali, A. M. Abdulla, Z. R. Zhu, K. G. Juma, V. A. Dyck, A. R. Msangi, P. A. Mkonyi, and H. U. Feldmann. 2000. Glossina austeni (Diptera: Glossinidae) eradicated on the island of Unguja, Zanzibar, using the sterile insect technique. Journal of Economic Entomology 93: 123-135. https://doi.org/10.1603/0022-0493-93.1.123

Vreysen, M. J. B., K. M. Saleh, R. Lancelot, and J. Bouyer. 2011. Factory tsetse flies must behave like wild flies: a prerequisite for the sterile insect technique. PLOS Neglected Tropical Diseases 5(2): e907. https://doi.org/10.1371/journal.pntd.0000907

Vreysen, M. J. B., T. Balenghien, K. M. Saleh, S. Maiga, Z. Koudougou, G. Cecchi, and J. Bouyer. 2013. Release-recapture studies confirm dispersal of Glossina palpalis gambiensis between river basins in Mali. PLOS Neglected Tropical Diseases 7: e2022.

https://doi.org/10.1371/journal.pntd.0002022 